\title{
相関検波による平均周波数および平均電力の測定
}

\author{
小林 正 明*・大沢寿**森 永 規 彦***・滑川敏 彦***
}

\section{Mean Frequency and Mean Power Measurement Using Correlation Detection}

\author{
Masaaki Kobayashi*, Hisashi Osawa**, Norihiko Morinaga*** and Toshihiko Namekawa***
}

This paper is concerned with the problems of measuring the mean frequency and the mean power of a zero-mean, stationary, narrowband Gaussian random signal in the presence of additive Gaussian noise.

An experimental mean frequency measurement system using correlation detection is constructed for the purpose of obtaining practical characteristics. The average output and the output signal-to-noise ratio of the system obtained by experiment are compared with the theoretical values.

A new method for measuring the mean power is also described and analyzed. The new method utilizes the mean frequency measurement system, and the mean power of a Gaussian random signal is determined using a reference sine wave. The results of the theoretical analysis on this method are supporting by experiment.

\section{1. まえがき}

雑音状信号の電力スペクトル分布から信号源や信号 伝送路の性質を把握するため, 電力スペクトル分布の 推定あるいは平均周波数, 平均電力などそのパラメー タの検出が, 計測, 制御, 通信をはじめ工学各分野を 通じて重要な問題の一つとなっている，乙とに，雑音 状信号がガウス分布に従う場合その統計的諸性質は電 カスペクトル分布あるいは相関関数に集約されてお り，乙のような意味においても電力スペクトル分布や そのパラメータの検出が重要な問題となってくる.

†電子通信学会通信方式研究会で発表 (昭 $48 \cdot 6$ )

*, 三菱電機 (株) 通信機製作所 尼崎市南清水字中野 80

** 愛媛大学工学部 松山市文京町 3-1

*** 大阪大学工学部 吹田市字山田上

* Communication Equipment Works, Mitsubishi Electric Co., Ltd., Amagasaki

** Faculty of Engineering, Ehime University, Matsuyama

*** Faculty of Engineering, Osaka University, Suita (Received February 6, 1976)
電力スペクトル分布の平均周波数の測定法の一つに 零交さカウンタの一種で相関検波による平均周波数測

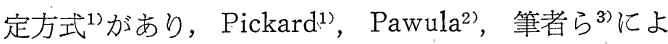
って理論解析がなされている. 一方, 平均電力の測定 法については，いわゆる Radiometer に関して従来か ら多くの研究がなされており，レベル交さ数を利用し たディジタル形 Radiometer ${ }^{4)}$ あ発表されている.レ ベル交さ形の平均電力測定法は, 雑音状信号のレベル 交さ数と平均電力の間にある一定の統計的性質に基ず いているが，レベルを設定するかわりに被測定雑音状 信号に基準正弦波を加えるととにより，上記零交さ形 の相関検波による平均周波数測定方式においても平均 電力の测定が可能となる.

そこで本稿では，相関検波による平均周波数測定方 式に関して筆者らが行った実験結果について報告する とともに，本方式を利用した平均電力測定法を新たに 提案しその測定原理と基本特性および実験結果につい て述べる.

\section{2. 基 本 構成}

本方式の基本構成を Fig. 1 亿示す. 本稿で扱う被 測定雑音状信号すなわち Fig. 1 の入力信号 $S(t)$ は, ある十分高い代表周波数のまわりに狭帯域の連続スぺ クトルをむつ雑音状信号で, 平均值 0 の定常狭帯域ガ ウス形ランダムプロセスと仮定する. $S(t)$ は平均周波 数(注 1)でまとめた狭帯域表示を用いるとつぎのよう に表現できる2).

$$
S(t)=x(t) \cos \left\{\left(\omega_{0}+\omega_{c}\right) t\right\}-y(t) \sin \left\{\left(\omega_{0}+\omega_{c}\right) t\right\}
$$

ただし， $x(t), y(t)$ はたがいに統計的に独立な平均 值 0 の低周波ガウス形ランダムプロセスで， $\omega_{0}, \omega_{c}$ は

（注1） $S(t)$ の電力スペクトル分布を $G_{s}(\omega)$ とすれば，平均 周波数 $\left(\omega_{0}+\omega_{c}\right)=\int_{0}^{\infty} \omega G_{s}(\omega) d \omega / \int_{0}^{\infty} G_{s}(\omega) d \omega$ で定義さ れる11. また，角周波数を単に周波数と記す. 


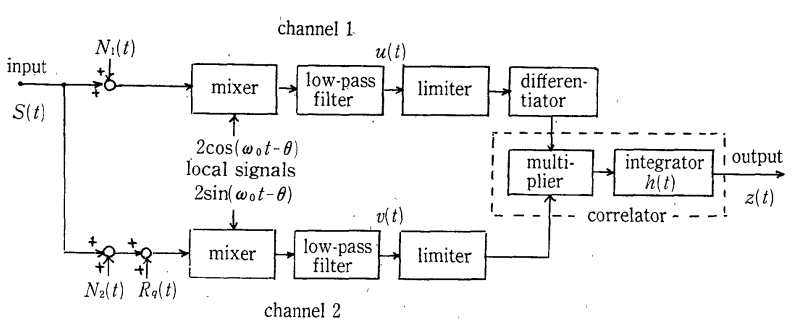

Fig. 1 Mean frequency and mean power measurement system using correlation detection

それぞれ局発信号の角周波数, $\omega_{0}$ 加らの角周波数偏差 である。また，各チャネルの入力雑音 $N_{1}(t), N_{2}(t)$ は たがいに拉よび信号とも統計的に独立な平均值 0 の定 常狭帯域ガウス形ランダムプロセス之仮定する.

平均電力測定の際，チャネル 2 の入力に加えられる 一定振幅 $Q$, 周波数 $\omega_{0}+\omega_{r}$ の基準正弦波を $R_{q}(t)$ と する・すなわち，

$$
R_{q}(t)=-Q \cos \left\{\left(\omega_{0}+\omega_{r}\right) t\right\}
$$

ただし，振幅 $Q$ は既知とする，なお，上式では計算 の便宜上，負号をつけ正弦波を余弦で表現している. 平均周波数測定の際は基準正弦波を加えず， $R_{q}(t) \equiv 0$ とする.

以上の入力各成分は周波数が $\omega_{0}$ で $90^{\circ}$ 位相の異な る二つの局発信号によって周波数変換され差周波数成 分がリミッタに加えられる．チャネル 1 怙よび 2 のリ ミッタ入力をそれぞれ $u(t), v(t)$ とすると

$$
\begin{aligned}
& u(t)=s_{1}(t)+n_{1}(t) \\
& v(t)=s_{2}(t)+n_{2}(t)+Q \sin \left(\omega_{r} t+\theta\right)
\end{aligned}
$$

ただし， $\omega_{r}$ は周波数変換後の基準正弦波の周波数， $s_{1}(t), s_{2}(t), n_{1}(t)$ およよび $n_{2}(t)$ はそれぞれ各チャネル のリミッタ入力の信号成分および雑音成分で $S(t)$, ， $N_{1}(t), N_{2}(t)$ が周波数変換されたものである.また， $\theta$ は局発信号の位相を表わし， 0 から $2 \pi$ で一様分布 し，他のすべての確率変数とは統計的に独立である.

こてで各チャネルのリミッタは，その入出力特性が つぎのように符号関数 sgn で与えられる理想リミッタ と仮定し，

$$
v_{\text {out }}=\operatorname{sgn} v_{\text {in }}= \begin{cases}+1, & v_{\text {in }} \geq 0 \\ -1, & v_{\text {in }}<0\end{cases}
$$

さらに, 積分器を理想積分器と仮定し, そのインパル スレスポンス $h(t)$ を

$$
h(t)=\left\{\begin{array}{l}
\pi / 2 T, \quad 0 \leq t \leq T \\
0, \quad t<0, \quad t>T
\end{array}\right.
$$

とすれば，時刻 $t$ における積分器出力，すなわち本方 式の出力 $z(t)$ は

$$
z(t)=\frac{\pi}{2 T} \int_{t-T}^{t} \operatorname{sgn} v(t)\left\{\frac{d}{d t} \operatorname{sgn} u(t)\right\} d t
$$

之表わさ机る，ただし， $T$ は積分時間を表わす。

\section{3. 測 定 原理}

\section{1 平均周波数の測定原理}

相関検波による平均周波数測定方式について は文献 1)〜3) で解析されており，ここではそ

の結果を用いて測定原理を簡単汇説明する.

入力信号 $S(t)$ は周波数変換されてリミッタ入力で は平均周波数が $\omega_{c}$ となっており, 以下 $\omega_{c}$ を信号の平 均周波数として扱う(注 2 )。 また, 平均周波数測定の際 には基準正弦波は加えないので， $R_{q}(t) \equiv 0$ とする.

出力の平均值 $\mathrm{E}[z(t)]$ は次式で与えられる ${ }^{1)}$.

$$
\mathrm{E}[z(t)]=\omega_{c} A, \quad A \equiv \sqrt{a_{1} a_{2} /\left(a_{1}+1\right)\left(a_{2}+1\right)}
$$

ただし，E[ ] はアアンサンブル平均を意味し， $a_{1}, a_{2}$ は 各チャネルの入力 $S N$ 比を表わす。すすねわ，

$$
\begin{aligned}
& a_{1}=P_{S} / P_{N 1}, \quad a_{2}=P_{S} / P_{N 2} \\
& P_{S}=\mathrm{E}\left[S^{2}(t)\right], \quad P_{N 1}=\mathrm{E}\left[N_{1}{ }^{2}(t)\right], \\
& P_{N 2}=\mathrm{E}\left[N_{2^{2}}(t)\right]
\end{aligned}
$$

(8) 式に示されるように出力の平均值は $\omega_{c} A$ とな り信号の平均周波数 $\omega_{c}$ に比例している(注 3 ). したが って, 積分時間が十分長いとき出力， $z(t)$ はほぼ一定 （直流）となり，出力の直流成分 $\omega_{c} A$ を読むととによ り信号の平均周波数を知るととができる. 信号の電力 スペクトル分布が特に対称な場合にはその中心周波数 之平均周波数は一致し，信号の中心周波数が測定され る.

出力の平均値は入力雑音の影響を受けて真値 $\omega_{c}$ の $A$ 倍 $(0 \leq A \leq 1)$ の值をとる. 入力雑音がない場合 $A$ $=1$ となるが, 入力雑音がある場合出力の直流レベル 隹入力 $S N$ 比 $a_{1}, a_{2}$ によって決まる一定の偏り（バ イアス） $A$ が生じ出力の較正が必要となる.ただし， 本方式は相関検波を用いているため入力雑音がたがい に統計的に独立であれば入力雑音の平均周波数は出力 の平均值に寄与せず，乙れに関する較正は不要で，入 力 $S N$ 比に関する較正のみを行えばよい.

積分時間 $T$ は有限のため出力には直流分の他に動摇 成分が生じてこれが測定誤差の原因となる，直流分を

（注 $2 ） \omega_{0}$ は既知であるから， $\omega_{c}$ が測定されれば，もとの 平均周波数 $\omega_{0}+\omega_{c}$ が求まる.

（注 3)，(1)式に打いて平均周波数でなく任意の代表周波数 でまとめた狭帯表示を用いてす（８)式の結果を得る 
出力の信号成分と定義し，そのまわりのゆらぎを出力 の雑音成分と定義すると, 本方式の出力 $S N$ 比 $(S / N)_{0}$ は次式で与えられる。

$$
(S / N)_{0}=\{\mathrm{E}[z(t)]\}^{2} /\left\{\mathrm{E}\left[z^{2}(t)\right]-(\mathrm{E}[z(t)])^{2}\right\}
$$

(10)式の出力 $S N$ 比は出力の正規化平均 2 乗誤差の逆 数を表わしており, 測定精度の目安となる ${ }^{3}$.

\section{2 平均電力の測定原理}

相関検波による平均周波数測定方式を応用し，基準 正弦波 $R_{q}(t)$ を用いて雑音状信号 $S(t)$ の平均電力(注 4 ) $P_{S}$.を測定するととができる、本節では基準正弦波を 加えた場合の出力の平均值を求め, 本方式の測定原理 および基本特性について述べる.

（7）式および，アンサンブル平均，時間積分，時間 微分の順序变更 ${ }^{5), 6)}$ により, 出力の平均値は

$\mathrm{E}[z(t)]$

$$
=\frac{\pi}{2 T} \int_{t-T}^{t}\left(-\frac{\partial}{\partial t} \mathrm{E}[\operatorname{sgn} v(t) \operatorname{sgn} u(t-\tau)]\right)_{\tau=0} d t
$$

となる・いま,

$$
\begin{aligned}
& y_{1} \equiv\left\{s_{1}(t-\tau)+n_{1}(t-\tau)\right\} / \sqrt{P_{S}+P_{N 1}} \\
& y_{2} \equiv\left\{s_{2}(t)+n_{2}(t)\right\} / \sqrt{P_{S}+P_{N 2}} \\
& r_{0} \equiv Q \sin \left(\omega_{r} t+\theta\right) / \sqrt{P_{S}+P_{N 2}}
\end{aligned}
$$

とおくと $y_{1}, y_{2}$ あまたガウス分布に従い，(11) 式右包 の平均演算は

$\mathrm{E}[\operatorname{sgn} v(t) \operatorname{sgn} u(t-\tau)]$

$$
=\mathrm{E}\left[\operatorname{sgn}\left(y_{2}+r_{0}\right) \operatorname{sgn} y_{1}\right]
$$

$$
\begin{aligned}
& \cdot \frac{2 \sqrt{2}}{\sqrt{\pi}} \int_{-\infty}^{-r_{0}} \exp \left(-\frac{y_{2}^{2}}{2}\right) \\
& \text { - } \operatorname{erf}\left\{-\lambda(\tau) y_{2} / \sqrt{1-\lambda^{2}(\tau)}\right\} d y_{2}
\end{aligned}
$$

となる・ただし，

$$
\operatorname{erf}(x)=\frac{2}{\sqrt{\pi}} \int_{0}^{x} e^{-t^{2} / 2} d t, \quad \lambda(\tau)=\mathrm{E}\left[y_{1} y_{2}\right]
$$

(11), (13)式より

$$
\begin{aligned}
\mathrm{E}[z(t)] & =\frac{\omega_{c} A}{T} \int_{t-T}^{t} \exp \left(-\frac{1}{2} r_{0}^{2}\right) d t \\
& =\frac{\omega_{c} A}{2 \pi} \int_{\phi-2 \pi}^{\phi} \exp \left[-\frac{Q^{2}}{2\left(P_{S}+P_{N 2}\right)} \sin ^{2} \phi\right] d \phi
\end{aligned}
$$

ただし， $\phi=\omega_{r} t+\theta, \omega_{r} T=2 \pi$

（注 4） 本稿では, 通信方式や雑音解析の分野でよく用いら れるように 平均電力と呼ぶことにする. したがって, 普通の電力が 必要なときは較正を行えばよい:
となる. (15)式の積分を行うとつぎのように出力の平 均值 $\mathrm{E}[z(t)]$ が求まる.

$\mathrm{E}[z(t)]$

$$
\begin{aligned}
& =\omega_{c} A \exp \left[-\frac{Q^{2}}{4\left(P_{S}+P_{N 2}\right)}\right] \cdot \mathrm{I}_{0}\left[\frac{Q^{2}}{4\left(P_{S}+P_{N 2}\right)}\right] \\
& =\omega_{c} A \exp \left[-\frac{a_{2}}{a_{2}+1} \frac{q}{2}\right] \cdot \mathrm{I}_{0}\left[\frac{a_{2}}{a_{2}+1} \frac{q}{2}\right] \quad(16)
\end{aligned}
$$

ただし， $\mathrm{I}_{0}(\cdot)$ は第 1 種 0 次変形 Bessel 関数， $q$ は基 準正弦波電力対被測定信号電力比で,

$$
q=Q^{2} / 2 P_{S}
$$

で定義される.

つぎに本方式の測定原理と基本特性について述べ る. まず, 入力雑音がなく $a_{1}=a_{2}=\infty(A=1)$ の場合, $\mathrm{E}[z(t)]=\omega_{c} \exp (-q / 2) \cdot \mathrm{I}_{0}(q / 2)$ 之なり, $\omega_{c}$ を既知とすれば出力の平均値すなわち出力 の直流レベルから $q$ が求まって, (17) 式とQの值から 被測定信号電力 $P_{S}$ が得られる。乙れが本方式の測定 原理である. 被測定信号 $S(t)$ の中心周波数 $\omega_{0}+\omega_{c}$ は 通常 (Radiometer の場合) 入力フィルタの中心周波 数であって， $\omega_{c}$ は既知之考えられる。あし未知なら ば基準正弦波を加えず $Q \equiv 0$ として測定することによ り $\omega_{c}$ が得られる. 以下， $\omega_{c}$ を既知亡して扱うととに する.

入力雑音が存在し $P_{N 1}=P_{N 2}$, したがって $a \equiv a_{1}=a$ の場合,

$$
\begin{aligned}
& \mathrm{E}[z(t)]=\omega_{c} A \exp (-q A / 2) \cdot \mathrm{I}_{0}(q A / 2), \\
& A=a /(a+1)
\end{aligned}
$$

之なる. 乙の場合, 入力雑音の平均電力が未知であっ ても，まず基準正弦波を加えずに $(Q=q=0)$ 測定し て $A$ を求め,つぎに基準正弦波を加えて測定し $(q \neq 0)$ $q A / 2$ を求めると, 両結果から $q$ が得られ $P_{S}$ を求め ることができる.

入力雑音の平均電力 $P_{N 1}, P_{N 2}$ が異なる場合には基 準正弦波の大きさを変えて 3 回 (1 回は $Q=0$ とす る）測定するてとにより $P_{S}$ が求まる7 .

このように本方式では較正用の標準雑音源を用いず に，未知の入力雑音電力と分離して $P_{S}$ を測定する ことができる. 入力雑音電力がすべて既知であれば $\mathrm{E}[z(t)]$ と $P_{S}$ の 1 対 1 の対応関係から，1 回の測定 で $P_{S}$ を得ることができる。 なお，本方式では基準正 弦波の周波数を被測定信号の中心周波数に一致させる 必要はなく任意の值に選べる。また，基準正弦波を于 ヤネル 1 亿加えても, チャネル 2 亿加えた場合と同様 の特性が得られる.

平均電力測定の際屯, 出力のゆらぎ成分に比べて直 流分が大であるほど高精度で被測定信号電力を求めう 
るので（10)式により出力 $S N$ 比を定義することがで きる.

レベル交さ形の平均電力測定法は被測定信号（ガウ ス形ランダムプロセスとする）のレベル $V_{0}$ の上问き (または下向き) の交さ数 $N_{V}$ の平均值 $\mathrm{E}\left[N_{V}\right]$ 之平 均電力 $P_{S}$ との間につぎの関係

$$
\mathrm{E}\left[N_{V}\right]=f_{z} T \exp \left(-V_{0}^{2} / 2 P_{S}\right)
$$

ただし， $f_{z}$ は被测定信号の単位時間当りの上向き (または下向言) の平均零交さ数， $T$ は計数時間，吕 成り立つととを利用している4．（18）式と(20)式を比 較すれば明らかかなように，レベル交さ形の測定法と 基準正弦波老用いる本方式とはその出力特性が類似し ていることがわかる。吉なわち，両方式上もガウス分 布を有する信号に対する同種の統計的特性を利用した 方式であって，レベル交さ形の測定法は平均出力をレ ベルにより較正して平均電力を測定するのに対し，本 方式は基準正弦波の振幅により較正して測定するとと になる. また，レベル交さ形, 本方式のいずれ屯計数形 の測定法を採っており積分器のかわりにパルスカウン タを用いてとあにディジタル処理による測定を行うこ とができる.電波天文における信号電力は通常 $10^{-15}$ $10^{-20} \mathrm{~W}$ 程度の微小電力であり ${ }^{9}$ ，信号の增幅が必要 上なる.ダイオードなどによる 2 乗則烩波器を利用し た Total Power Radiometer ${ }^{9)} や$ ，レベル交さ形の Radiometer と異なり，本方式による Radiometer は リミッタを用い入力に基準正弦波を加えるためそれ以 後の増幅器の利得変動に対して不感応であり, 原理的 に增幅器利得変動の影響を直接受けないという特長を 有している.

\section{4. 実 験 装 置}

Fig. 1 の構成の実験装置を試作し平均周波数 $\left(\omega_{0}+\right.$ $\left.\omega_{c}\right) / 2 \pi=500 \mathrm{kHz}$ の狭帯域ガウス雑音を被測定信号之 して実験在行った．被測定信号の実效帯域幅8) $\omega_{b}$ は

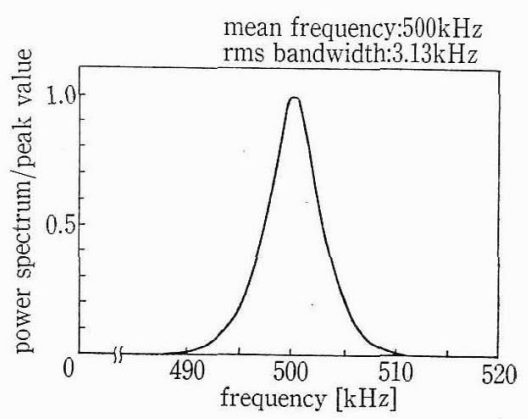

Fig. 2 Power spectrum of the input signal used in experiment $\omega_{b} / 2 \pi=3.13 \mathrm{kHz}$ で，その電力スペクトル分布は $\mathbf{F i g} 。$ 2 に示すような形をしている。 ほか心，二つの独立な 狭帯域ガウス雑音を各チャネルの入力雑音として用い たがそれらの電力スペクトル分布の形は Fig. 2 と同 様である. 䒠験では局発信号の周波数学可変とし被湘 定信号の周波数变換後の平均周波数 $\omega_{c} / 2 \pi$ t $0 \mathrm{~Hz} \sim$ $100 \mathrm{kHz}$ の範囲内にとった。微分器として時定数 $3 \times$ $10^{-8} \sec の C R$ 微分回路を用い, 積分器として $R C$ 1段の積分回路を用いた， $R C$ 積分回路の積分時間を 定義するた好等価積分時間9”導入した。 $R C$ 積分器 の時定数を $T_{R C}$ とすれば，等価積分時間 $T_{e}$ は $T_{e}$ $=2 T_{R C}$ で与えられる. 実験では $(6)$ 式の $T$ と等佂な 積分時間として $T$ eを用いた。

\section{5. 実験結果および検討}

まず，平均周波数測定を例にとって各部の波形例を Fig. 3 に示す. 同図(a), (b)は掛算器出力の波形を 示している. 図中の正のパルス数と負のパルス数の差

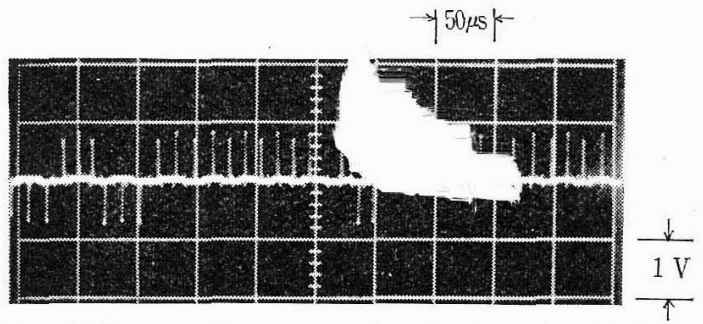

(a) multiplier output for $a_{1}=a_{2}=1\left\{\omega_{c} / 2 \pi=37.0 \mathrm{kHz}, \omega_{b} / 2 \pi=3.13 \mathrm{kHz}\right\}$.

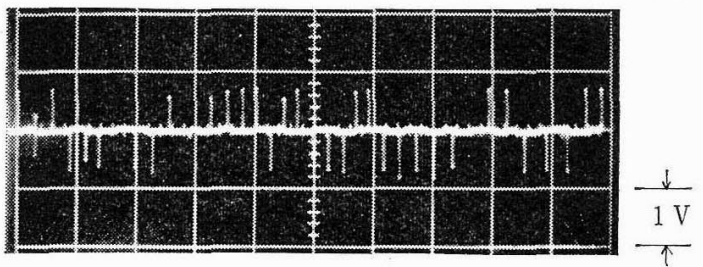

(b) multiplier output for $a_{1}=a_{2}=0$

$\mathrm{E}[z(t)]$

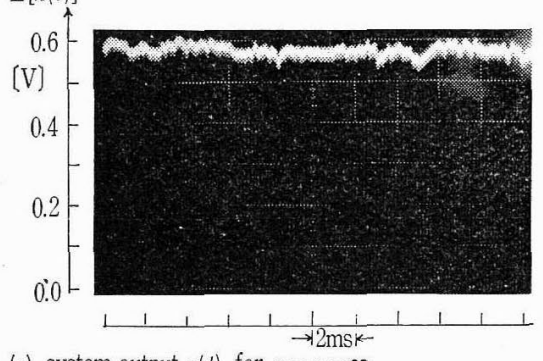

(c) system output $z(t)$ for $a_{1}=a_{2}=\infty$ ( $\left.\omega c / 2 \pi=43.0 \mathrm{kHz}, \omega_{b} / 2 \pi=3.13 \mathrm{kHz}, T_{e}=0.6 \mathrm{~ms}\right)$.

Fig. 3 Observed waveformsof the multiplier output and the system output 


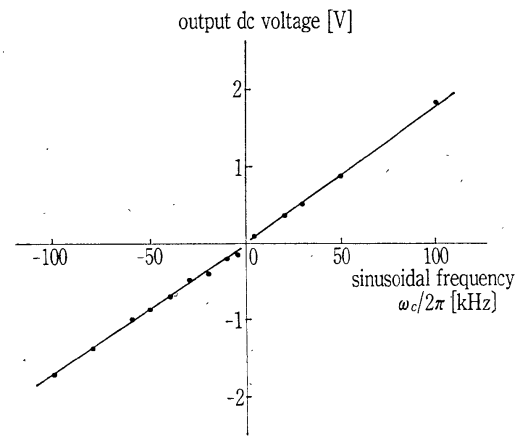

Fig. 4 Output characteristic of the mean frequency measurement system for sinusoidal input in the absence of input noises

飞比例した直流成分が出力 $z(t)$ 飞現われる（8) 式 より入力信号がない場合 $\left(a_{1}=a_{2}=0\right)$ 出力の平均值は 0 となるが，同図(b)にみられるようにこの場合正負 両パルス数がほぼ等しく, 波形例から屯出力の直流成 分が 0 となるととがわかる. Fig. 3(c) は出力 $z(t)$ の 波形例を示している: 同図の直流レベルが出力の平均 值 $E[z(t)]$ 亿相当する場合，積分時間が十分大きくな いため出力のゆらぎが認められる.

平均電力測定の際 , Fig. 3 之同様の波形が得られ る.

\section{1 平均周波数測定}

はじめに; Fig. 4 に入力信号を特に正弦波とした場 合の試作装置の出力特性を示す. 入力正弦波, 周波数 に対する出力の直線性は良く, 積分回路の時定数を適 当な值にとれば $F M$ 信号の復調を行うことができる.

つぎに，入力信号が狭帯域ガウス雑音の場合の測定 結果を示す. Fig. 5 は入力雑音による出力のバイア スを, Fig. 6 は出力 $S N$ 比を示している. ただし， Fig. 6 の実線は理論值ではなく, 実験結果を結んだ曲 線である. Fig. 5 にみられるようにバイア゙スの実験值

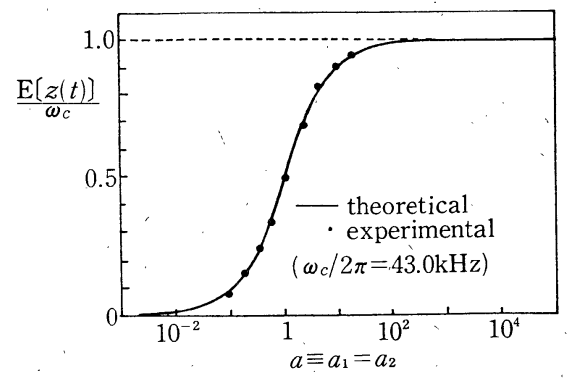

Fig. 5 Average output of the mean frequency measurement system

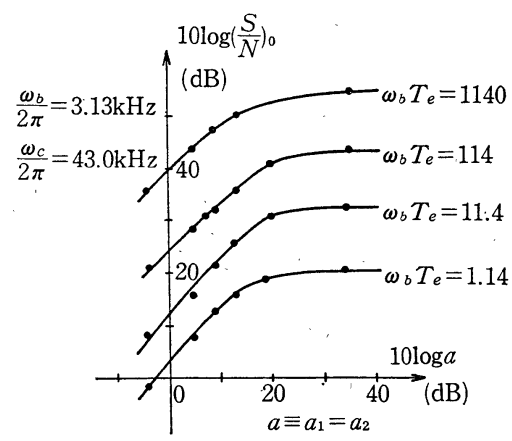

Fig. 6 Output SNR of the experimental mean frequency measurement system versus input SNR $a=a_{1}=a_{2}$

は(8)式による理論値とよく合っている. 出力 $S N$ 比 は積分時間を増すにつれて大きくなる. Fig. 6 の出力

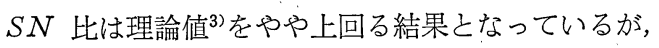
これは実験で用いた出力の分散測定回路中の直流分除 去回路がゆらぎ成分の一部をあ除去しているためであ ると考えられる. しかし, 出力 $S N$ 比の入力 $S N$ 比 に対する変化の模㥞は理論解析結果と一致している.

\section{2 平均電力測定}

実験に扔いては $a \equiv a_{1}=a_{2}=\infty(A=1)$ の場合およ び $a \equiv a_{1}=a_{2}=1(A=0.5)$ の場合について測定を行 った. Fig. 7 に出力の平均值を, Fig. 8 亿出力 $S N$ 比を示す. Fig. 7 の実験值は (16)式あるい!(19)式に

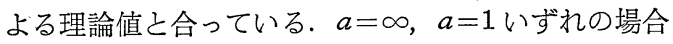
屯出力の平均值から横軸 $q$ の值が求められ, $q$ と基準 正弦波の振幅 $Q$ 加ら被測定信号電力 $P_{S}$ を得る. Fig. 8 の出力 $S N$ 比は積分時間が 10 倍になると $10 \mathrm{~dB}$ 上 昇して抢り, 平均周波数測定の際の出力 $S N$ 比特性と 同様である. 平均電力, 平均周波数のどちらも積分時 間を十分大きくとるととにより高精度で測定できる.

なお，本方式による平均電力測定法はレベル交さ形 測定法と同様測定信号がガウス分布しているととに基

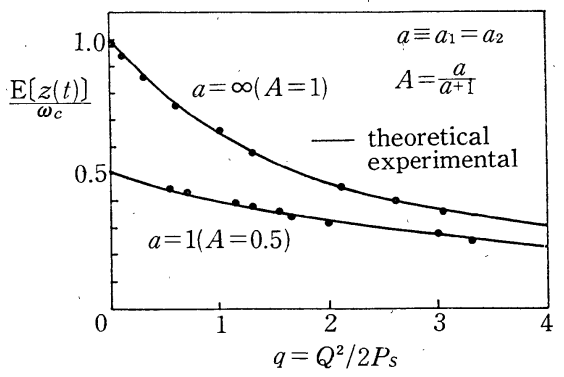

Fig. 7 Average output of the mean power measurement system 


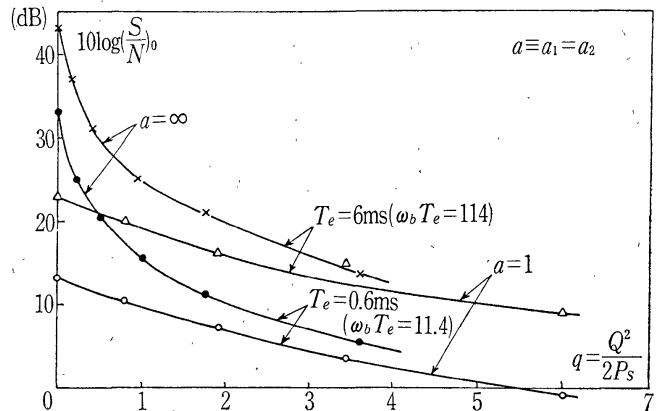

Fig. 8 Output SNR of the experimental mean power measurement system

づいており，確率分布が変われば出力特性も異なって くる.したがって正弦波を被測定信号とすることはで きない.

\section{6. むす び}

相関検波による平均周波数測定方式に関して試作装 置による実験的考察を加え, 動作内容および基本特性 を検証した．さらに，これを利用した平均電力測定法 を新しく提案しその測定原理を述べ基本特性を明らか にするととあに，実験によりその裹付けを行った．乙 れらの結果は本方式を活用する際の有用な資料になる あのと考えられる.
おわりに，実験装置の製作と測定にご協力いただい た静谷治氏 (現在, 松下電器産業 (株) 勤務) ならびに 筆者の一人が，日頃ご指導いただく愛媛大学田崎三郎 教授に深く感謝の意を表します。

\section{参 考 文 献}

1) T.B. Pickard: The Effect of Noise upon a Method of Frequency Measurement, IRE Trans., IT-4, 83/88 (1958)

2) R.B. Pawula: Analysis of an Estimator of the Center Frequency of a Power Spectrum, IEEE Trans., IT-14, 669/676 (1968)

3）小林, 大沢, 森永, 滑川：相関検波による平均周波数測 定方式の出力 $S N$ 比, 電子通信学会論文誌, 56-B-9, 379/386 (1973)

4) M.E. Tiuri and S. J. Halme: Digital Measurement of Narrowband Noise Power, Proc. IEEE; 55, 1577/1582 (1967)

5) W.B. Davenport, Jr. and W. L. Root: An Introduction to the Theory of Random Signals and Noise, p. 65, McGraw-Hill, New York (1958)

6) D. Middleton: An Introduction to Statistical Communication Theory, p. 68, McGraw-Hill, New York (1960)

7）小林; 大沢, 森永, 滑川：雑音電力の零交さ型測定方 式, 電子通信学会通信方式研究会資料, CS 73-66(1973)

8) N.M. Blachman: Noise and Its Effect on Communication, p. 42, McGrow-Hill, New York (1966)

9) M.E. Tiuri: Radio Astronomy Receivers, IEEE Trans., AP-12, 930/938 (1964) 